\title{
El monasterio de San Isidro de Dueñas en la Edad Media (911-1478). Estudio y colección documental
}

\section{Carlos Manuel Reglero de la Fuente}

\section{Q OpenEdition \\ 1 Journals}

Édition électronique

URL : https://journals.openedition.org/cem/11147

DOI : 10.4000/cem. 11147

ISSN : 1954-3093

\section{Éditeur}

Centre d'études médiévales Saint-Germain d'Auxerre

\section{Édition imprimée}

Date de publication : 15 août 2009

Pagination : $397-400$

ISSN : 1623-5770

\section{Référence électronique}

Carlos Manuel Reglero de la Fuente, «El monasterio de San Isidro de Dueñas en la Edad Media

(911-1478). Estudio y colección documental », Bulletin du centre d'études médiévales d'Auxerre / BUCEMA [En ligne], 13 | 2009, mis en ligne le 08 septembre 2009, consulté le 22 septembre 2022. URL : http:// journals.openedition.org/cem/11147; DOI : https://doi.org/10.4000/cem.11147

Ce document a été généré automatiquement le 22 septembre 2022.

\section{(c) (i) (9)}

Creative Commons - Attribution - Pas d'Utilisation Commerciale - Partage dans les Mêmes Conditions 4.0 International - CC BY-NC-SA 4.0

https://creativecommons.org/licenses/by-nc-sa/4.0/ 


\title{
El monasterio de San Isidro de Dueñas en la Edad Media (911-1478). Estudio y colección documental
}

\author{
Carlos Manuel Reglero de la Fuente
}

1 Entre las ciudades de Palencia y Valladolid se encuentra el monasterio de San Isidro de Dueñas, que fue el primer priorato cluniacense en el reino de León (1073) y hoy continúa habitado por monjes de La Trapa. Este trabajo parte del primer documento conocido (911) y concluye con la unión de San Isidro a la Observancia de San Benito de Valladolid (1478).

2 El monasterio de San Isidro de Dueñas parece que fue fundado poco antes de su primera mención documental (911), pues los intentos de remontarlo a época visigoda tienen escasa base. Su dominio monástico, ofrece un panorama similar al de otros monasterios benedictinos de los reinos de Castilla y León estudiados en las últimas décadas. La antigüedad de su fundación explica el temprano desarrollo de su dominio, que atraviesa una primera fase de expansión en la primera mitad del siglo X y una segunda entre los años 1073 y 1130. Tras una larga etapa de estabilidad, los problemas se sucedieron desde fines del siglo XIII : la fiscalidad de los reyes y de los abades de cluny obligó a empeñar numerosas heredades, entrando en una espiral de deudas y enajenaciones de bienes de la que no se salió hasta mediados del siglo XV, a menudo por la vía de ceder a nobles y concejos las heredades del monasterio mediante censos a perpetuidad. Los siglos XIII-XV fueron también una época de múltiples litigios con obispos y nobles. Con los primeros por el cobro de los diezmos y el ejercicio de otros derechos eclesiásticos en las iglesias que pertenecían al monasterio, con los segundos por las heredades que se les habían arrendado bajo condiciones contrarias a los estatutos de la Orden de Cluny.

3 Si estos caracteres son similares a los de otros monasterios, hay algunos que son específicos de los prioratos cluniacenses. Así el control ejercido sobre la gestión del dominio por el abad, el capítulo general, el camarero y los visitadores de 
Cluny; el papel de los priores y oficiales monásticos llegados de Francia; la transferencia de bienes entre los prioratos cluniacenses hispanos. También ello explica la sujeción temporal a San Isidro de otros tres prioratos: San Boal de Carraciello, cerca de Cuellar - donado a San Isidro por el conde Pedro Ansúrez -, Santiago del Val y Santa Coloma de Burgos - donados directamente a Cluny por el rey Alfonso VI. Todos ellos se independizaron de Dueñas desde fines del siglo XIII.

Se ha prestado especial atención a las relaciones entre San Isidro de Dueñas y los reyes y nobles del reino. Durante el siglo X el monasterio gozó de la protección primero de los reyes de León y luego de los condes de Monzón. En el siglo XI e inicios del XII, los benefactores del monasterio fueron de nuevo los reyes, desde Sancho III el Mayor a Urraca, y en especial Alfonso VI. Junto a los reyes, las grandes familias de la comarca y sus vasallos realizaron importantes donaciones : los Beni Gómez de Carrión, los Alfonso y la familia del conde Pedro Ansúrez, en la que confluían las dos anteriores.

5 La protección real y nobiliaria se difumina conforme avanza el siglo XII, aunque se consiguiese mantener el contacto con la monarquía a través de personajes como el conde Nuño de Lara o magister Geraldo, un antiguo notario de Alfonso VIII y arcediano de Palencia. Desde fines del siglo XIII San Isidro se relaciona sobre todo con miembros de la nobleza comarcal castellana, como los Cabeza de Vaca, Padilla o Hermosilla, alternando la protección y el conflicto. El contacto con la monarquía se recuperó en época de los Reyes Católicos, a través del conde Pedro de Acuña, señor de Dueñas. Ahí están las bases del nuevo renacer económico y espiritual de San Isidro a través de su afiliación a la Observancia de San Benito de Valladolid.

Otro foco de atención ha sido el estudio de la comunidad monástica que lo habitaba. Poco se sabe sobre ella en los primeros siglos, salvo que decía seguir la regla de San Benito y que no se trataba de un monasterio familiar. En 1073 Alfonso VI donó San Isidro de Dueñas a Cluny, convirtiéndole en el primer monasterio del reino de León que dependía de un cenobio francés. Tras ello la abadía se transformó en priorato, su comunidad se integró en la ecclesia cluniacensis, y su prior pasó a ser designado por el abad de Cluny o, por delegación, por el camarero de Cluny en España. Las primeras décadas de la etapa cluniacense constituyen uno de los periodos de esplendor de San Isidro, pues entonces actuó de hecho como el centro de los dominios y monasterios de Cluny en España, en especial bajo su primer prior, el monje Roberto. Desde los años 1120-1130 fue relegado a un segundo término por el monasterio de San Zoilo de Carrión, junto al Camino de Santiago, mejor situado para comunicarse con Francia, y que se convirtió en sede de los camareros de Hispania.

7 San Isidro fue un priorato de tamaño medio, con una docena de monjes en los siglos XII-XIII. Su organización y su liturgia derivaban de la de Cluny, pero adaptadas al menor número de monjes. Los estudios prosopográficos permiten ver como los priores y monjes de San Isidro procedían o pasaban a otros monasterios de Cluny en España, siempre bajo la autoridad del camarero o del abad. La residencia del camarero de España en el cercano monasterio de San Zoilo de Carrión durante la mayor parte de los siglos XII-XIV acentuaba esta influencia y control sobre San Isidro.

8 Los problemas económicos y de gestión de San Isidro en el siglo XIV se reflejan también en el plano disciplinario. La situación empeoró considerablemente en la 
primera mitad del XIV, con numerosos altibajos, que tocan fondo en medio de la oleada de Peste Negra en 1349. La quema del monasterio durante la guerra civil que enfrentó a Pedro I y Enrique II (1366-1369) acentuó la crisis, de la que no se empezó a salir hasta mediados del XV. El monasterio arrastraba desde fines del XIII un grave problema: la falta de monjes, que hicieron que durante algunos momentos sólo estuviese habitado por su prior. Fue esta falta de monjes la que llevó a su último prior, Pedro de Belorado, a solicitar la unión a la Observancia de San Benito de Valladolid (1478), separándose de Cluny.

El conocimiento de este monasterio choca con el problema de las fuentes. La edición de la colección documental prometida por Charles Julian Bishko nunca vio la luz. Sí que han sido publicados buena parte de los documentos reales así como los del antiguo archivo de Cluny. Casi todos los documentos originales del antiguo archivo monástico se han perdido. Los pergaminos originales que han sobrevivido proceden de otros centros - Catedral de Palencia, San Zoilo de Carrión, Cluny. Por ello esta colección documental está compuesta mayoritariamente de copias o resúmenes, de calidad muy desigual, procedentes de 8 archivos y bibliotecas. Ello exigió una importante labor de crítica documental para corregir los numerosos documentos mal datados e identificar los falsos; labor que no siempre ha sido posible por lo incompleto del documento : de los 174 recogidos en la colección sólo 37 están completos. Se incluyen índices onomástico y toponímico de los documentos.

INDEX

Index géographique : Espagne/San Isidro de Dueñas 